American J. of Engineering and Applied Sciences 1 (4): 318-323, 2008

ISSN 1941-7020

(C) 2008 Science Publications

\title{
Crack Growth in Concrete Gravity Dams Based on Discrete Crack Method
}

\author{
${ }^{1}$ A.R. Lohrasbi and ${ }^{2}$ R. Attarnejad \\ ${ }^{1}$ Department of Civil Engineering, School of Civil Engineering, \\ University of Tehran, Tehran, Iran \\ ${ }^{2}$ School of Civil Engineering, University of Tehran, Tehran, Iran
}

\begin{abstract}
Seepage is the most parameter in water management safety and in stable agricultural. This seepage is passed through the cracks that are present to some degree in hydraulic structures. They may exist as basic defects in the constituent materials or may be induced in construction or during service life. To avoid such failure in concrete dams, safety would be an important factor. Over-design carries heavy penalty in terms of excess weight. So the fracture mechanics theory is a principal necessity of evaluating the stability of such crack propagation. For the process of crack propagation analysis in concrete structures, there are two general models: discrete crack and smeared crack. This study surveys the crack propagation in concrete gravity dams based on discrete crack methods. Moreover, we use a program provided specifically for this purpose.
\end{abstract}

Key words: Concrete, gravity dam, fracture, crack propagation, discrete crack

\section{INTRODUCTION}

Seepage is the most parameter in water management safety. This seepage is passed through the cracks that are present to some degree in hydraulic structures. They may exist as basic defects in the constituent materials or may be induced in construction or during service life.

The phenomenon of failure by catastrophic crack propagation in structural materials poses problems of design and analysis in many fields of engineering. One important area when considering such failure is the civil engineering in which safety is of paramount importance. Therefore fracture mechanics theory is the fundamental requirement of assessing the stability of crack propagation.

Considerable effort has been devoted in recent years to understanding and developing numerical models for the mechanical behaviour of civil engineering structures and industrial components made of brittle materials.It is clear now that the main difficulties in the models are related to the localization processes associated with the creation of cracks and their propagation. To accurately predict fracture behaviour, it is necessary to use finite element analysis $^{[1,2]}$.
Fracture mechanics concepts: A crack which is present in a loaded body can be deformed in different ways. Irwin observed that there are three independent kinematical movements of the upper and lower crack surfaces with respect to each other and these are categorized as:

Opening mode, I: In which the two crack surfaces are pulled apart in the $y$ direction, but where the deformations are symmetric about the $x-z$ and $x-y$ planes (Fig. 1).

Shearing mode, II: In which the two crack surfaces slide over each other in the $\mathrm{x}$ direction, but where the deformations are symmetric about the $x-y$ plane and skew symmetric about the $\mathrm{x}-\mathrm{z}$ plane (Fig. 2).

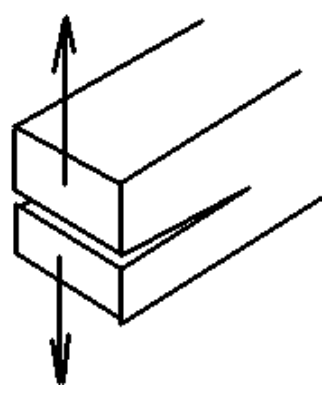

Fig. 1: Opening mode I

Corresponding Author: A.R. Lohrasbi, Department of Civil Engineering, School of Civil Engineering, University of Tehran, Tehran, Iran 


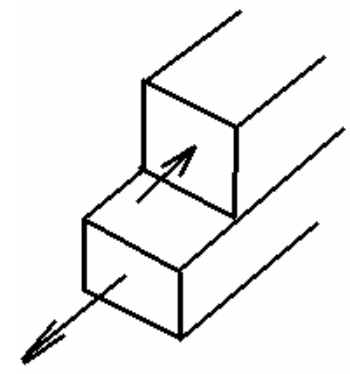

Fig. 2: Shearing mode II

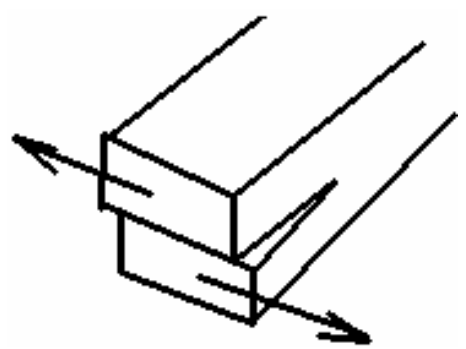

Fig. 3: Tearing mode III

Tearing mode, III: In which the crack surfaces slide over each other in the $\mathrm{z}$ direction, but where the deformations are skew-symmetric about the $x-y$ and $x-z$ planes (Fig. 3).

Thus it can be seen that any crack deformation can be represented by the appropriate superposition of these three cases. Irwin showed that the primary stress components in the crack tip region corresponding to the three displacement modes could be expressed in the following form:

$$
\sigma_{y}=\frac{K_{I}}{(2 \pi r)^{\frac{1}{2}}} f(\theta), \sigma_{x y}=\frac{K_{I I}}{(2 \pi r)^{\frac{1}{2}}} f(\theta), \sigma_{y z}=\frac{K_{I I I}}{(2 \pi r)^{\frac{1}{2}}} f(\theta)
$$

In the above, $r$ is the radial distance from the crack tip and the terms $f(\theta)$ are functions of the polar angle $\theta$ only. It is seen that stress field possesses s singularity of strength $1 / \sqrt{\mathrm{r}}$ at the crack tip. The parameters $\mathrm{K}_{\mathrm{I}}$, $\mathrm{K}_{\mathrm{II}}$ and $\mathrm{K}_{\mathrm{III}}$ are shown as the stress intensity factors corresponding to the three cracking modes and they characterize the magnitude of the crack tip stress field.

The stress intensity factors are related to the appropriate strain energy release rate $(\mathrm{G})$ expressions. For example for mode I opening crack, $\mathrm{K}_{\mathrm{I}}$ is related to $\mathrm{G}$, as followed:

$\mathrm{G}_{\mathrm{I}}=\frac{(\mathrm{k}+1)}{8 \mu} \mathrm{K}_{\mathrm{I}}^{2}$

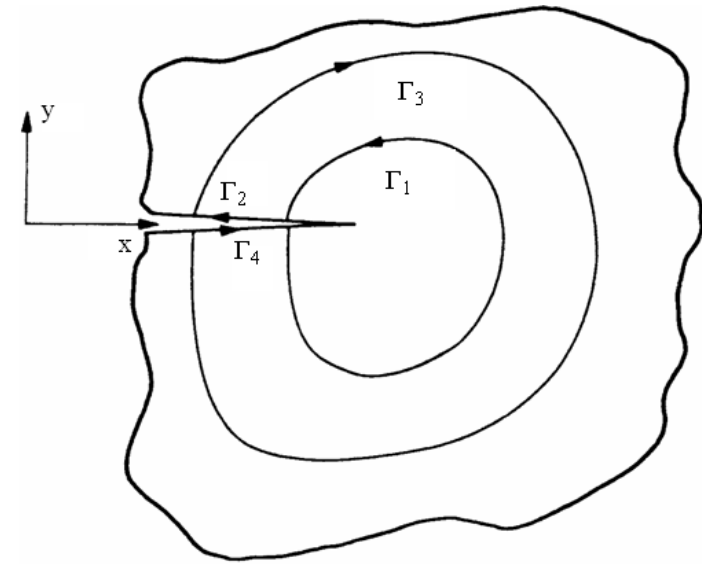

Fig. 4: J-Integral path ${ }^{[4]}$

In which $\mu$ is the shear modulus of the material and for plane strain:

$\mathrm{k}=3-4 \mathrm{v}$

And for plane stress:

$\mathrm{k}=\frac{3-\mathrm{v}}{1+\mathrm{v}}$

Similarity, the relations for the other two deformation modes are ${ }^{[3]}$ :

$\mathrm{G}_{\mathrm{II}}=\frac{(\mathrm{k}+1)}{8 \mu} \mathrm{K}_{\mathrm{II}}^{2}, \mathrm{G}_{\mathrm{III}}=\frac{(\mathrm{k}+1)}{8 \mu} \mathrm{K}_{\mathrm{III}}^{2}$

The stress intensity factor can also be related to a path independent integral presented by. With reference to Fig. 4 it can be shown that the following line integral, termed the J-Integral, is independent of the actual path chosen, provided that the initial and end points of the contour $\Gamma$ are on opposite faces of the crack and that the contour contains the crack tip:

$\mathrm{J}=\int_{\Gamma}\left(\mathrm{Udy}-\mathrm{t}_{\mathrm{i}} \frac{\partial \mathrm{u}_{\mathrm{i}}}{\partial \mathrm{x}} \mathrm{ds}\right)$

In which:

$\mathrm{U}=$ The strain energy density

$\mathrm{t}_{\mathrm{i}}=$ The traction vector

$\mathrm{u}_{\mathrm{i}}=$ The displacement vector

$\mathrm{ds}=$ An element of arc along the integration contour, $\Gamma$

For linear and nonlinear fracture problems it can be shown, for each particular mode of deformation, that ${ }^{[4]}$ : 
$\mathrm{G}=\mathbf{J}$

Crack model: Fracture is an important mode of deformation and damage in both plain and unreinforced concrete structures. To predict the accuracy of fracture behavior, using finite element analysis would be essential. From among the most important reports in finite element analysis of concrete fracture, is ACI

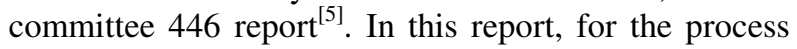
of crack propagation analysis in concrete structures, there are two general models: discrete crack and smeared crack.

Smeared crack model: Smeared crack method is based on two essential steps. The first step is to detect the place of initial crack, and the second one is to estimate the crack path, and to replace it with a soften element. The smeared crack approach implies a continuum type representation with a fixed Finite Element mesh. In this method, crack depends on the concrete materials and it will happen when the stress exceeds of allowable amount. The smeared crack model can consist of two parts: one is initial part of the crack that determines the orientation and location of a new crack, and the other one is the developed part where tractions and displacements of the crack opening is determined by the softening law.

Discrete crack method: Discrete crack method is known as natural crack model. Methods pertaining to the discrete crack approach calculate each crack individually in an explicit way in the Finite Element mesh. After pioneering works in which cracks would be allowed to open between exist continuum elements according to a maximum stress criterion, procedures for general crack propagation with remeshing were developed for concrete structures. In the past, this remeshing process has been a tedious and difficult job, relegated to the analyst. Newer software techniques now enable the remeshing process, at least in twodimensional problems. The fracture process zone may be defined as the area surrounding a crack tip in which inelastic material behavior occurs. In very large concrete structures (ex. dams) it is possible to apply linear elastic fracture method appropriately.

Program algorithm: To survey the function of a concrete gravity dam under load needs some appropriate numerical tool in order to measure cracked concrete behavior. Thus for discrete crack analysis in concrete gravity dam some programs have been provided in FORTRAN.

For discrete crack method the following steps should be done one after the other:
- Detect of the location of the first crack. The first step in the crack propagation is detecting the place in which the crack starts. In this model, the assumption is that crack start from location which the principal stress exceeds the allowable tension stress which is approximately 10 percent of compact stress. When the first crack location is determined, this location will be saved and another crack is started from the end of pervious crack

In this subroutine, $\mathrm{y}$ is variable between 0 and $\mathrm{H}$ .Each section that the stress exceeds of tension stress is the first crack location. The loads that apply to this model are:

$$
\left.\begin{array}{l}
\mathrm{P}_{1}=\frac{\gamma(\mathrm{H}-\mathrm{y})^{2}}{2} \\
\mathrm{P}_{2}=\gamma_{\mathrm{C}} \mathrm{A}_{2}=2.4 \gamma \mathrm{a}(\mathrm{h}-\mathrm{y}) \\
\mathrm{P}_{3}=\gamma_{\mathrm{C}} \mathrm{A}_{3}=\frac{2.4 \gamma(\mathrm{x}-\mathrm{a})(\mathrm{h}-\mathrm{y})}{2} \\
\sigma=\frac{\mathrm{P}}{\mathrm{A}}-\frac{\mathrm{Mc}}{\mathrm{I}} \\
\mathrm{M}=\mathrm{P}_{1} \times \frac{\mathrm{H}-\mathrm{y}}{3}
\end{array}\right\} \sigma=\frac{\mathrm{P}_{2}+\mathrm{P}_{3}}{\mathrm{x}}-
$$

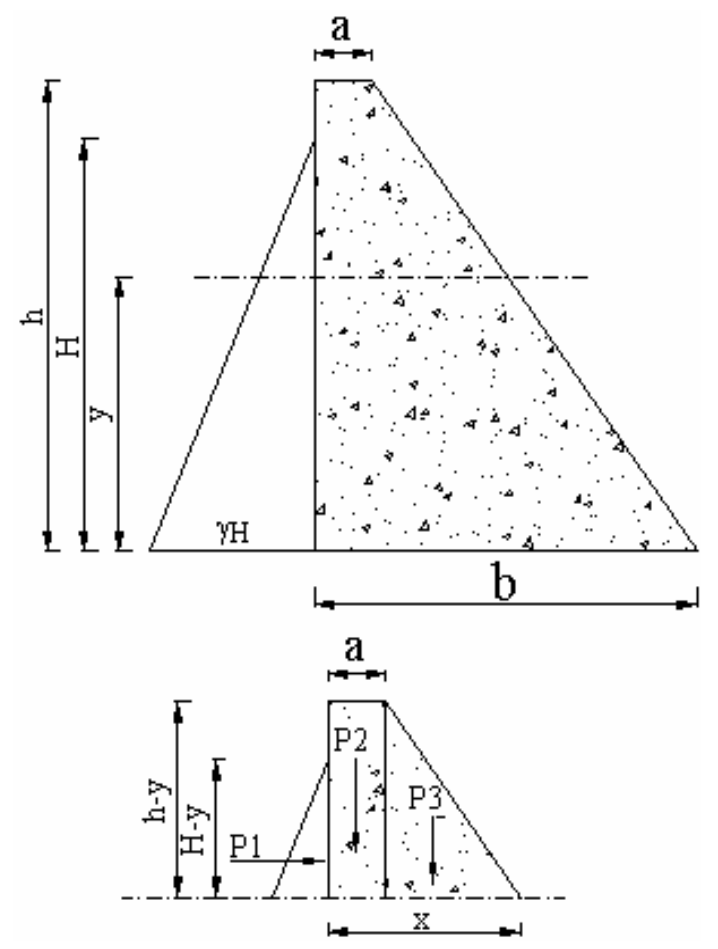

Fig. 5: Detect of the location of the first crack 


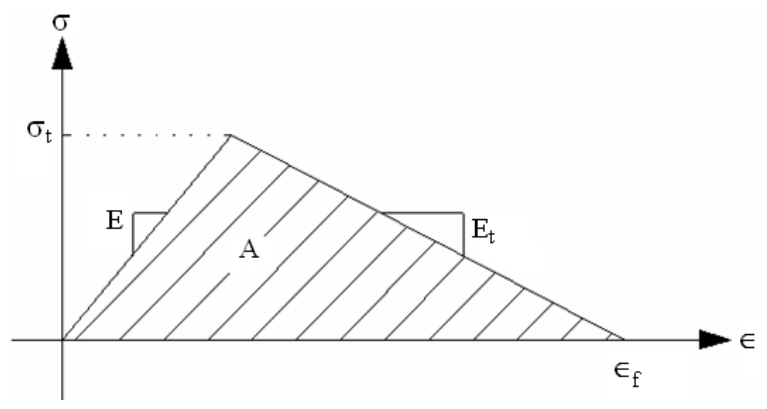

Fig. 6: Stress-strain curve

- An initial meshing will be done. Meshing process has been a tedious and difficult job. So a subroutine has been made for meshing and remeshing in concrete dam

To reach the element size, we do as mentioned in Fig. 6.

That $\mathrm{G}_{\mathrm{f}}$ (critical energy release rate) equals ${ }^{[6]}$ :

$\mathrm{G}_{\mathrm{f}}=\mathrm{Ah}$

$\mathrm{A}$ is under area of Stress-Strain curve and $\mathrm{h}$ is element size.

On the one hand, we have:

$\mathrm{G}_{\mathrm{f}}=\frac{1}{2} \sigma_{\mathrm{t}}^{2}\left(\frac{1}{\mathrm{E}}-\frac{1}{\mathrm{E}_{\mathrm{t}}}\right) \mathrm{h}$

Or:

$$
E_{t}=\frac{\sigma_{t} E h}{\sigma_{t}^{2} h-2 G_{f} E}
$$

So, the critical element size gets from this equal:

$h_{c}=\frac{2 \mathrm{EG}_{\mathrm{f}}}{\sigma_{\mathrm{t}}^{2}}$

- The load factor is started from 0.1

- With this load factor, some analysis will be done on the present meshing

- For finding the plastic point around crack tip, J integral has been used

The J-Integral method for determining the energy release rate of the opening mode (I) crack is useful, not only for linear fracture problems, but also for nonlinear fracture problems. For a two-dimensional problem,

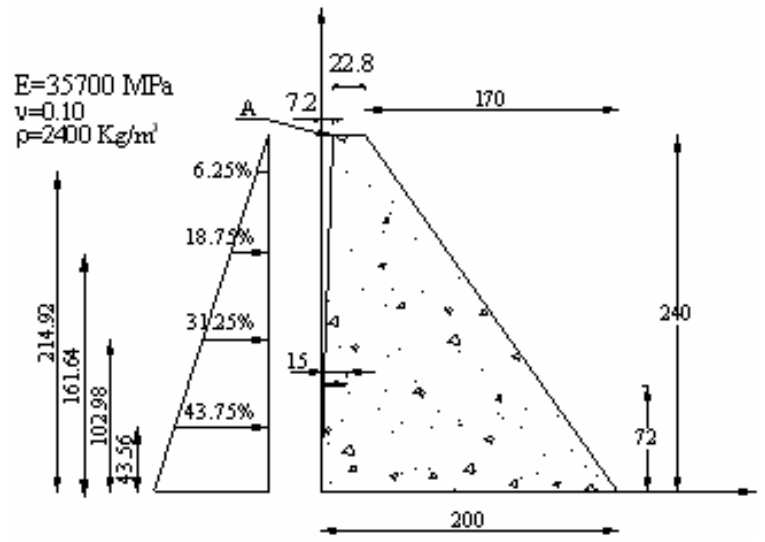

Fig. 7-Dam model ${ }^{[7]}$

a path $\Gamma$ is traversed in a counter-clockwise sense between the two crack surfaces (Fig. 4).

If in $\mathbf{J}$ integral path, a plastic point was found, it shows crack has moved to that point and program goes to next step. If not, load factor is small and must be increased. Then program goes to step 8 .

- The crack propagates and goes to plastic point.

- New meshing will be done

- The load factor will be increased

- The program goes to step 4

Numerical example: Let us now examine the behavior of a gravity dam model whose dimensions are shown in Fig. 7. This experimental test was performed without dynamic loading. The hydraulic thrust was generated by means of servo controlled actuator with a $2000 \mathrm{kN}$ capacity and applied to upstream side ${ }^{[7]}$.

This force was distributed in four concentrated loads whose intensity is shown in Fig. 7. Notch depths were taken to be 15 , and, the specimen thickness was $30 \mathrm{~cm}$.

Our program has modeled this dam. Load factor increases and crack propagates (Fig. 8).

To check the accuracy of our program, the crack mouth opening displacement and the displacement of point A (Fig. 7) in experimental test has been compared with numerical model.

The comparison of program results with experimental test shows that we can use this program for crack propagation model.

Load versus displacement of point $\mathrm{A}$ in model (Fig. 7), by smeared crack and discrete crack method, has been shown in Fig. 11. 

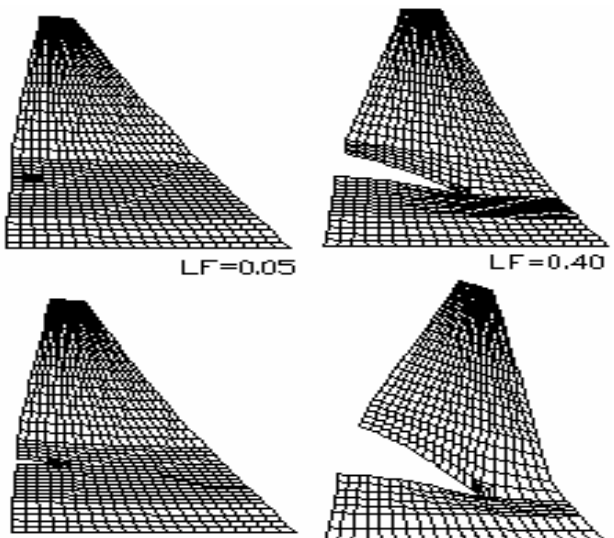

LF $=0.12$
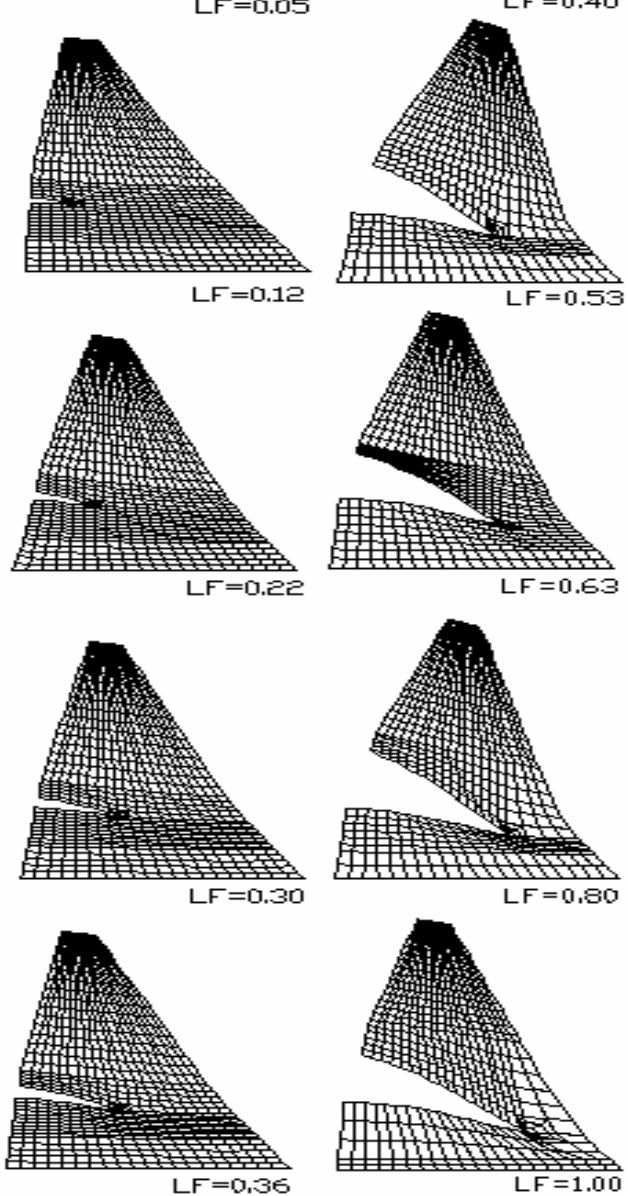

Fig. 8: Crack propagation

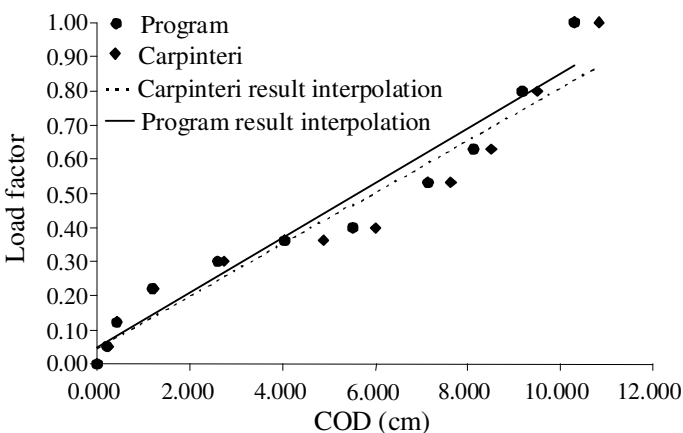

Fig. 9: The comparison of crack mouth opening displacement in experimental test with numerical model

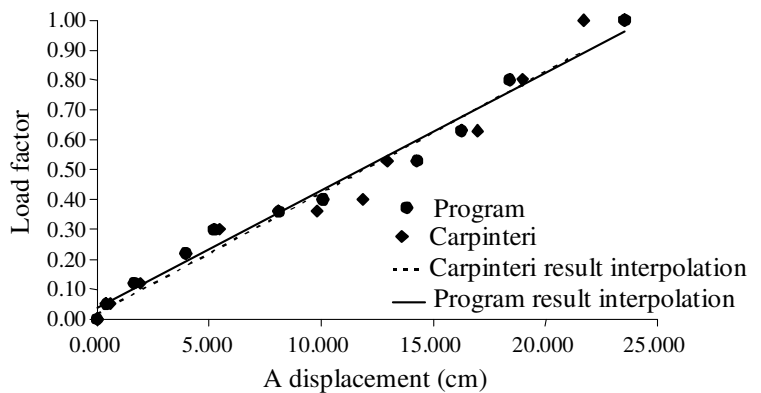

Fig. 10: The comparison of displacement of point A in experimental test with numerical model

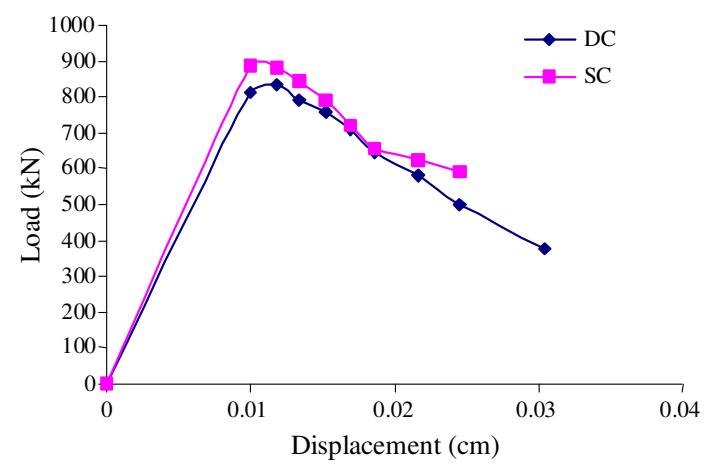

Fig. 11: Load versus displacement of point A of Fig. 7

\section{CONCLUSION}

In the present study for the process of crack propagation analysis in concrete structures, smeared crack and discrete crack models have been used in a computer programs.

To check the accuracy of the program, the experimental test has been compared with numerical model.

These results, show that smeared crack method give unacceptable results.

The advantage of discrete crack method is the demonstration of the real crack and its opening. This opening makes possible the measuring of water pressure penetrated to crack. This method's deficiency is an expense of time and money because of frequent meshing.

In comparison with discrete crack, smeared crack method is simple and less consuming time and money. Its deficiency is that the nature of the crack is not real, because of the replacement of isotropic, elastic and linear behavior with an orthotropic one. Furthermore, it would be impossible to measure the crack opening or the pressure of penetrating water. 
With this program, we can apply earthquake loads by load factors and get useful information for new designs.

The accuracy of calculation depends on the mesh size.

\section{REFERENCES}

1. Owen, D.R.J. and A.J. Hinton, 1979. An Introduction to Finite Element. 1st Edn., Pineridge Press Ltd., Swansea, UK.

2. Owen, D.R.J. and E. Hinton, 1977. Finite Element Programming. 1st Edn., Academic Press Inc. London Ltd., UK.

3. Owen, D.R.J. and E. Hinton, 1983. Finite Element in Plasticity. 1st Edn., Pineridge Press Ltd., Swansea, UK.

4. Owen, D.R.J. and A.J. Fawkes, 1983. Engineering Fracture Mechanics: Numerical Methods and Applications. 1st Edn., Pineridge Press Ltd., Swansea, UK., ISBN: 10: 0906674263, pp: 305.
5. American Concrete Institute, 1997. Finite element analysis of fracture in concrete structures: State-of-the-art. http://aec.ihs.com/document/abstract/KRBSCAAA AAAAAAAA.

6. Ahmadi, M.T. and J. Amiri, 1998. Modeling of concrete materials behavior in nonlinear dynamic analyses in gravity dams. Proceeding of the 4th International Conference on Civil Engineering, April.

7. Barpi, F. and S. Valente, 2000. Numerical simulation of prenotched gravity dam models. J. Eng. $\quad$ Mech, 126: 611-619. http://scitation.aip.org/getabs/servlet/GetabsServlet ?prog=normal\&id=JENMDT00012600000600061 $1000001 \&$ idtype $=$ cvips \& gifs $=$ yes. 